\title{
Performance and Characterization of Aloe Vera Microcapsules on Silk/Lyocell Blended Fabric
}

\author{
Mariyam Adnan ${ }^{1}$, Jeyakodi Moses $\mathbf{J}^{2}$ \\ ${ }^{1}$ Department of Apparel and Fashion Design, PSG College of Technology, Peelamedu, Coimbatore, 641004, Tamil Nadu, India \\ ${ }^{2}$ Department of Applied Science, PSG College of Technology, Peelamedu, Coimbatore, 641004, Tamil Nadu, India
}

Corresponding Author: Mariyam Adnan, mariyam.ag@gmail.com

\begin{abstract}
In this study, silk and lyocell fibers were blended in the ratio of 50:50 and woven into a plain weave fabric. Aloe vera based microcapsules were used to impart antibacterial finish on silk/lyocell blended fabrics and assessed by SEM, EDX, FTIR, agar diffusion test, bacterial reduction test, and wash durability test. SEM analysis showed aloe vera capsules impregnated in the fabric. EDX also showed the presence of aloe vera in the fabric by showing the presence of chemical elements like $\mathrm{Mg}, \mathrm{Ca}, \mathrm{K}$, $\mathrm{Al}$ and $\mathrm{Fe}$ which were not present in the untreated fabric. FTIR spectra of aloe vera treated samples showed an ether group, a secondary alcohol group, an aromatic group and a nitro group that reveal the probable chromophoric groups likely to be present in the aloe vera gel. The results of agar diffusion test clearly show that aloe vera treated fabrics have very good antibacterial properties and do not allow the growth of bacteria in the treated fabric. The zone of inhibition was found to be very good and ranged from $28 \mathrm{~mm}$ to $30 \mathrm{~mm}$. Bacterial reduction test showed the percentage reduction values of both the microorganisms $S$. aureus and E. coli to be more than $97 \%$. The wash durability of aloe vera treated fabrics lasted up to 25 washes.
\end{abstract}

\author{
ARTICLE HISTORY \\ Received: 04.02.2019 \\ Accepted: 11.10.2019
}

\section{KEYWORDS}

aloe vera, lyocell, silk, microencapsulation, antibacterial

\section{INTRODUCTION}

Silk is a natural fiber priced for its vanity, versatility, wearability and comfort. In spite of all the wonderful properties silk possesses, it is extremely costly [1]. Lyocell is a regenerated cellulosic fiber which offers luxury, less cost and surpasses all other cellulosic fibers in terms of properties, aesthetics and importantly ecofriendliness in manufacturing [2]. Lyocell is $100 \%$ natural in origin, has better dyeability than other cellulosics, softness and drape, luxurious handle, good moisture retention and hence wearing comfort, and good dimensional stability. Notably, lyocell fiber blends well with various natural and synthetic fibers, like cotton, linen, rayon, polyester, lycra, nylon, silk and wool. The stress-strain characteristics of lyocell make it an ideal partner with the various textile fibers [2].

In this study, silk and lyocell were blended so that one can enjoy the richness of silk and excellent softness of lyocell. Since, silk and lyocell belong to the category of protein and cellulosic fibers respectively; they are prone to microbial attack and can be damaged easily. Therefore, their protection against microbes becomes imperative to preserve their individual properties and widen its spectrum of applications $[1,2]$.

The use of natural agents such as chitosan, neem and natural dyes for antimicrobial finishing of textiles has been widely reported [3]. Aloe vera (Aloe barbadensis) is known 'Lily of the desert' and belongs to the family Liliaceae. The aloe leaf consists of two major parts, the outer green rind and the inner colourless parenchyma containing the aloe gel [4]. Polysaccharides in aloe gel are mainly responsible for their antimicrobial activity. There are different polysaccahrides in aloe vera such as glucoga, glucomannan, galactogalacturan and lactomannan with different composition as well as acetylated acemannan. Acemannan is a long chain polymer consisting of randomly acetylated linear D-mannopyranosyl units having antibacterial and antifungal properties [5]. 
Jayakumari et al [6] found some important bioactive constituents such as P-methyl benzoic acid, 2-thiophene carboxylic acid and dimethyl 4-chlorophenyl thiophosphate having antibacterial activities were found by subjecting the aloe vera extract to the Gas Chromatography Mass Spectroscopy (GC-MS). This study highlights the use of aloe vera as an effective antibacterial agent.

Irshad et al [7] studied the antibacterial activity of aloe vera which showed that aloe vera extract of methanol gave the maximum antibacterial activity as compared to other solvent extracts. A major limitation in antimicrobial finishing with natural agents is the non-durability of the finish. Finishing by microencapsulation method can increase the durability of antimicrobial finish on textiles as it offers many advantages compared to conventional process, in terms of economy, eco-friendliness and controlled release of substance [8-10].

Kamble et al [11] tested the antimicrobial activity of aloe vera extract against bacteria and found that methanol extract showed maximum inhibitory activity against $E$. coli and Candida. Fatemeh [12] identified, quantified, and compared the phytochemical contents, antioxidant properties, and antibacterial activities of Aloe vera lyophilized leaf gel and $95 \%$ ethanol leaf gel extracts.

Although considerable research work has been carried out in the past on the medical uses of aloe vera, its antibacterial activity on textile substrate is not widely reported. The present work aims at developing a natural antibacterial finish on silk/lyocell blended fabric using aloe vera microcapsules.

\section{MATERIAL AND METHOD}

\subsection{Material}

A blended yarn containing silk/lyocell in the ratio of 50:50 (S/L 50:50) was manufactured in a spinning unit in Coimbatore, Tamil Nadu, India and processed to produce $60 \mathrm{~s}$ Ne (9.84 tex) yarn. The blended yarn was constructed into a plain woven fabric with the specifications of warp density 30 ends/cm, weft density $25 \mathrm{picks} / \mathrm{cm}$, and fabric density of $71.8 \mathrm{~g} / \mathrm{m}^{2}$. Aloe vera (Aloe barbadensis) was collected from the forest department, Coimbatore, Tamil $\mathrm{Nadu}$, India. Acacia gum, citric acid, methanol and sodium sulphate were purchased from a chemical factory in Tirupur, Tamil Nadu, India.

\subsection{Method}

\subsubsection{Aloe vera extraction}

The leaves of aloe vera were washed with lukewarm water. The aloe vera gel was then extracted from the leaves and stored in a clean glass vessel, dried in hot air oven at $75^{\circ} \mathrm{C}$ for two days and then powdered. $20 \mathrm{~g}$ of powdered aloe vera was dispersed in $100 \mathrm{ml}$ of methanol (1: 5 ratio of aloe vera: solvent) and extracted after 24 hours. Methanol was removed, by exposing it to open air. This aloe vera extract was used as an antibacterial finishing agent [13-15].

\subsubsection{Microencapsulation finish}

Microcapsules were done using aloe vera extract as core material $(75 \% \mathrm{w} / \mathrm{w})$ and gum acacia as wall material $(25 \%$ $\mathrm{w} / \mathrm{w}) .10 \mathrm{~g}$ of gum acacia was allowed to swell for thirty minutes by mixing with $100 \mathrm{ml}$ of hot water. This mixture was stirred well for $15 \mathrm{~min}$ at $50^{\circ} \mathrm{C}$ by adding another 50 $\mathrm{ml}$ of hot water. $1.5 \%$ (owf) methanol extracts of aloe vera was then added slowly, stirred at 300-500 rpm for further $15 \mathrm{~min}$ followed by drop wise addition of $20 \%$ (owf) sodium sulphate solution. The stirrer speed was reduced and $6 \%$ (owf) citric acid was added as a binding agent. The stirrer was stopped and mixture was then kept in a freezer overnight to develop the microcapsules. The S/L 50:50 fabric was immersed in the microcapsule solution for one hour using pneumatic padding mangle with a wet pick up of $80 \%$, dried at $80^{\circ} \mathrm{C}$ for $3 \mathrm{~min}$ and cured at $110^{\circ} \mathrm{C}$ for $2 \mathrm{~min}$ on a lab model curing chamber [8].

\subsubsection{Characterization of treated fabrics}

Surface morphology of the untreated and aloe vera treated fabric samples were examined by scanning electron microscope (SEM) JEOL JSM 6396, Japan. Energy dispersive X-ray (EDX) was carried out using a system fitted on the SEM which allowed identification of the elements present in the surface of the S/L 50:50 blended fabrics. The Fourier transform infrared (FTIR) spectrum for the untreated and aloe vera treated samples was obtained using Shimadzu FTIR - 8400S, Kyoto, Japan.

\subsubsection{Assessment of antibacterial activity}

The antibacterial activity of untreated and aloe vera treated fabrics by microencapsulation method were evaluated qualitatively using the AGAR diffusion method according to AATCC 147-2004 and quantitatively using the Shake Flask method according to AATCC 100-2004. The bacterial species Staphylococcus aureus ( $S$. aureus) and Escherichia coli (E. coli) were used as a representative gram positive and gram negative bacteria respectively.

\subsubsection{Wash durability}

The wash fastness of the aloe vera treated S/L 50:50 blended fabrics in terms of percentage reduction of bacteria was evaluated quantitatively by shake flask method (AATCC 100-2004) after subjecting the samples to 1, 5, 10, 15,20 and 25 home launderings as per the AATCC 1352004 method. The samples were washed using a standard detergent $\left(2 \%\right.$ owf) at $40^{\circ} \mathrm{C}$ for $10 \mathrm{~min}$ [13].

\section{RESULTS AND DISCUSSION}

\subsection{Characterization}

\subsubsection{SEM analysis}

The SEM photographs of untreated and aloe vera treated S/L 50:50 blended fabrics are shown in Figures 1(a) and 1(b) respectively. The treated fabric clearly shows a heavy 
deposition of aloe vera microcapsules on the fiber surface as seen from the Figure 1(b) when compared to the untreated fabric in Figure 1(a). It is in correlation to the earlier results that the microcapsules are fixed firmly on the fiber assembly of the fabric $[13,16]$.

\subsubsection{EDX analysis}

An elemental analysis of the particles was carried out by scanning electron microscope equipped with energy disperse X-ray spectrum (EDS), which provides a rapid qualitative and quantitative analysis of the elemental composition. Figure 2 shows the EDX graphs of untreated and aloe vera treated fabrics. Figure 2(b) reveals the presence of aloe vera in the treated fabric when compared to the untreated fabric (Figure 2a). The aloe vera treated fabric shows the presence of inorganic elements such as calcium, chlorine, iron, magnesium, potassium, phosphorous and sodium which are not present in the untreated fabric [1]

(a)
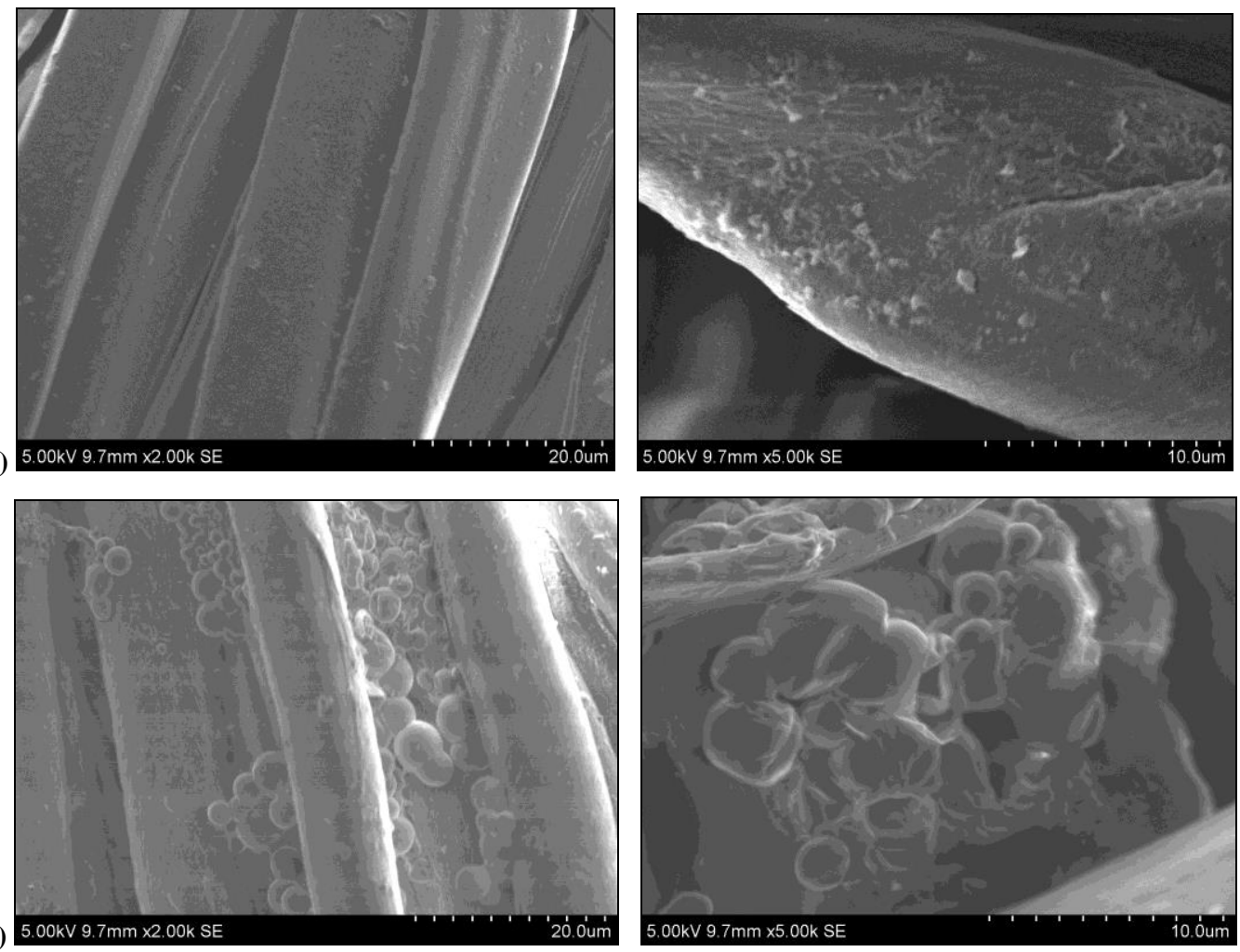

Figure 1. SEM images of (a) Untreated and (b) Aloe Vera Treated S/L 50:50 blended fabrics

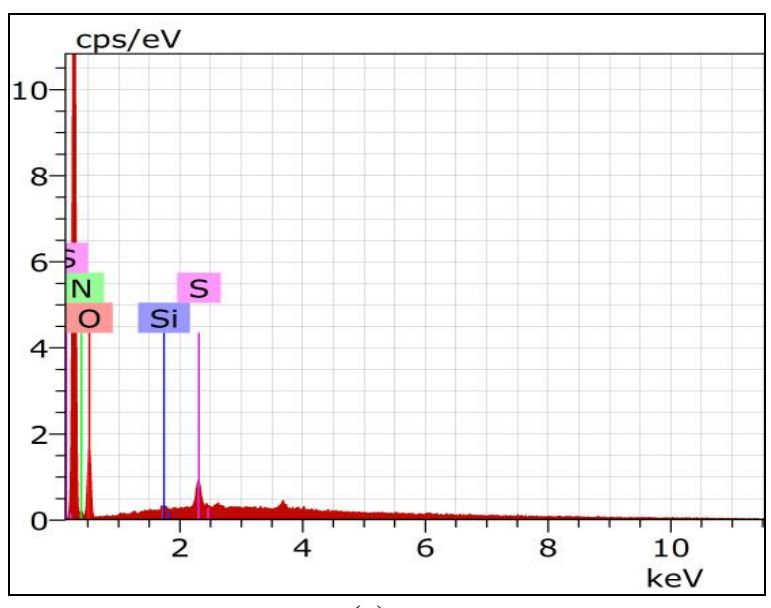

(a)

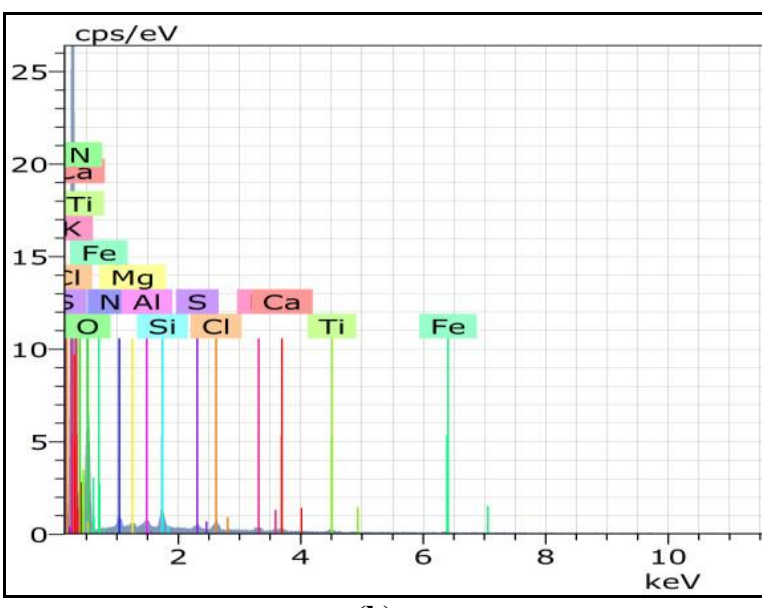

(b)

Figure 2. EDX Graphs of (a) Untreated (b) Aloe Vera Treated S/L 50:50 Blended Fabrics 


\subsubsection{FTIR analysis}

FTIR analysis was carried out using FTIR spectrophotometer. Figure 3 shows the FTIR spectra of both untreated and aloe vera treated S/L 50:50 blended fabric. In comparison with the FTIR spectra of untreated S/L 50:50, the spectrum of aloe vera treated S/L 50:50 samples show bands of ether R-OR group at $1047 \mathrm{~cm}^{-1}$ and secondary alcohol R-OH group at $1158 \mathrm{~cm}^{-1}$. An ether ROOR group is seen at $1230 \mathrm{~cm}^{-1}$ and an aromatic group is seen at $1443 \mathrm{~cm}^{-1}$. A band of nitro NO2 group is also seen at $1516 \mathrm{~cm}^{-1}$. These bands show the probable chromophoric groups likely to be present in the gel of aloe vera [17]. The strong absorption band at $1620-1610 \mathrm{~cm}^{-1}$ is due to $\mathrm{C}=\mathrm{C}$ stretching which indicates the presence of vinyl ether and aloin compound [18].

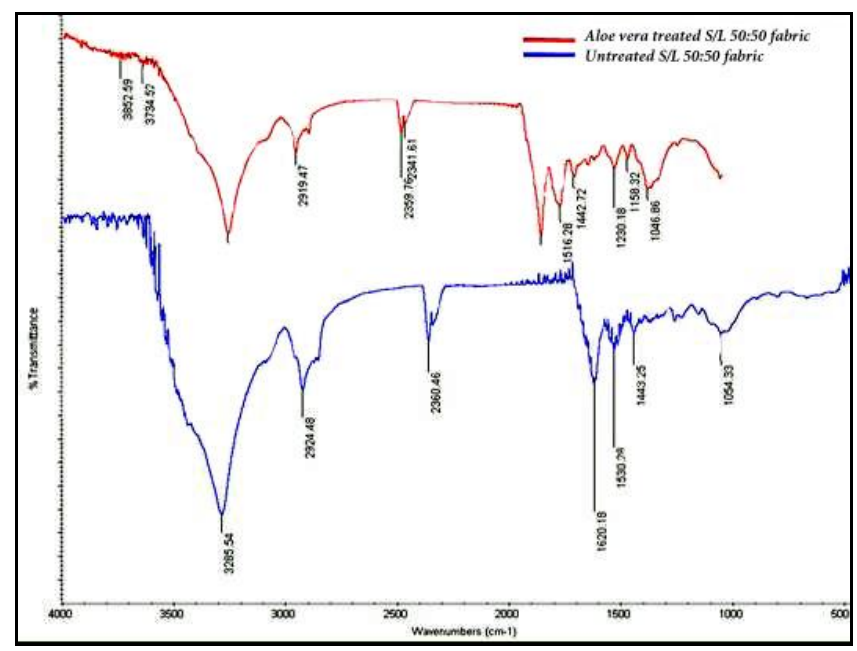

Figure 3. FTIR Spectra of Untreated and Aloe Vera Treated S/L 50:50 Blended Fabrics

\subsection{Antibacterial efficacy of aloe vera treated fabrics}

\subsubsection{Qualitative evaluation}

Antibacterial activities of aloe vera were determined qualitatively using Agar Diffusion Test on S/L 50:50 blended fabrics. The results are shown in Table 1.

Table 1. Qualitative Evaluation of Antibacterial Activity on Untreated and Aloe Vera Treated S/L 50:50 Blended Fabrics

\begin{tabular}{lll}
\hline \multirow{2}{*}{ Silk/Lyocell Fabrics } & \multicolumn{2}{l}{ Zone of inhibition $(\mathbf{m m})$} \\
\cline { 2 - 3 } & S. aureus & E. coli \\
\hline Untreated S/L 50:50 & Nil & Nil \\
Aloe Vera Treated S/L 50:50 & $30 \pm 0.2$ & $28 \pm 0.2$ \\
\hline
\end{tabular}

The results of qualitative analysis by microencapsulation method clearly show that the aloe vera treated S/L 50:50 blended fabrics have very good antibacterial properties to both gram positive (S. aureus) and gram negative (E. coli) bacteria. The aloe vera treatments do not allow the growth of bacteria on the treated fabric. The microencapsulation treated fabrics reveal a zone of inhibition of $30 \mathrm{~mm}$ for $S$. aureus (Figure 4a) and $28 \mathrm{~mm}$ for E. coli (Figure 4b). The antibacterial efficacy of aloe vera is found to be better against $S$. aureus than E. coli.

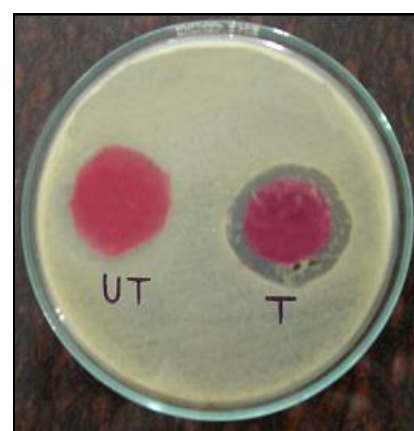

(a)

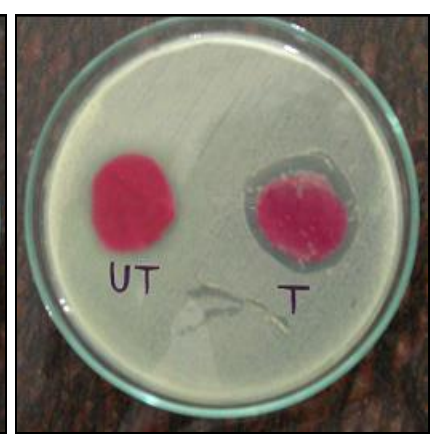

(b)
Figure 4. Antibacterial Activity of Untreated (UT) and Aloe Vera Treated (T) S/L 50:50 Blended Fabrics for (a) S. aureus and (b) E. coli

\subsubsection{Quantitative evaluation}

Antibacterial activities of aloe vera were determined quantitatively using Shake Flask Method by bacterial reduction percentage on S/L 50:50 blended fabrics. The results are shown in Table 2.

Table 2. Quantitative Evaluation of Antibacterial Activity on Untreated and Aloe Vera Treated S/L 50:50 Blended Fabrics

\begin{tabular}{lll}
\hline \multirow{2}{*}{ Silk/Lyocell Fabrics } & \multicolumn{2}{l}{ Bacterial reduction $(\%)$} \\
\cline { 2 - 3 } & S. aureus & E. coli \\
\hline Untreated S/L 50:50 & 0 & 0 \\
Aloe Vera Treated S/L 50:50 & 97.8 & 97.5 \\
\hline
\end{tabular}

Quantitative results indicate that the percentage reduction value of both the microorganisms $S$. aureus and E. coli were found to be more than $97 \%$ as seen from Table 2 . The untreated S/L 50:50 blended fabric showed 0\% reduction to both the microorganisms. The zone of inhibition values as seen in Table 1 indicates that the aloe vera treatment not only prevents the growth of bacteria in the S/L 50:50 fabric, but also leaches out and reduces the growth of bacteria. This is in agreement with the test results of \% reduction values. Similar results were obtained by Sathianarayanan et al $[16,19]$ in an earlier study.

\subsection{Wash durability}

The wash durability of aloe vera finishes by microencapsulation method on S/L 50:50 blended fabric is tested quantitatively by shake flask method in terms of bacterial reduction \% and are shown in Table 3.

Table 3. Wash Durability of Aloe Vera Treated S/L 50:50 Blended Fabrics by Quantitative Method

\begin{tabular}{ccc}
\hline Number of Washes & S. aureus & E. coli \\
\hline 0 & 97.8 & 97.5 \\
1 & 92.2 & 90.4 \\
5 & 89.2 & 85.3 \\
10 & 79.6 & 76.1 \\
15 & 67.1 & 55.3 \\
20 & 50.7 & 42.6 \\
25 & 42.1 & 39.3 \\
\hline
\end{tabular}


It is seen from Table 3 that the aloe vera microencapsulation treated fabrics are found to be excellent in the initial stage, and after subsequent washing up to 25 cycles also the effect is not reduced much. After every wash cycle, the antibacterial activity gradually decreases and at the end of 25 th wash cycle the percentage reduction goes down to $42.1 \%$ and $39.3 \%$ for $S$. aureus and E. coli respectively. The reason of good durability to washing may be attributed to the sustained release of aloe vera microcapsules over repeated laundering from the aloe vera extract because of the microencapsulation technique [20, 21]. These results were similar to reports of microencapsulation of neem, Mexican daisy, tulsi, pomegranate and ajwain applied on cellulosic materials in an earlier study $[16,19]$.

\section{CONCLUSION}

Following conclusions were drawn from the study conducted to evaluate the efficacy of antibacterial finish using aloe vera. Aloe vera microcapsules were found to have good antibacterial properties on silk/lyocell 50:50 blended fabrics to gram positive $S$. aureus as well as gram negative $E$. coli bacteria. S/L 50:50 fabrics treated with microcapsules of aloe vera were also found to have good wash durability up to 25 washes. SEM study revealed a better penetration of finish and bondage between the fibre molecules. EDX and FTIR analysis confirm the presence of aloe vera on silk/lyocell 50:50 blended fabrics by exhibiting compounds present in aloe vera gel. Also, both silk/lyocell bended fabric as well as aloe vera is $100 \%$ natural, having eco-friendly properties thereby giving economic, social and environmental benefits and can very well serve as a suitable alternative to conventional harmful chemicals.

\section{ACKNOWLEDGEMENT}

The authors wish to thank the Management and the Principal, PSG College of Technology, Coimbatore for given the permission and providing the necessary infrastructure. Thanks are also due to The Head, Department of Textile Technology for the kind help in department laboratory supports.

\section{REFERENCES}

1. Vinay GN, Sanjeev RS. 2015. Antimicrobial activity of silk treated with aloe-vera Fibers and Polymers 16(5), 1012-1019.

2. Vinay GN, Sanjeev RS. 2017. Antimicrobial treatment of silk with silver nanoparticles using acrylic binder Indian Journal of Fibre \& Textile Research 42, 465-473.

3. Joshi M, Ali SW, Rajendran S. 2007. Antibacterial finishing of polyester/cotton blend fabrics using neem (azadirachta indica): a natural bioactive agent Journal of Applied Polymer Science 106, 793 800 .

4. Reynolds T. 2004. Aloes: the genus aloe. Florida: CRC Press LLC.

5. Jothi D. 2009. Experimental study on antimicrobial activity of cotton fabric treated with aloe gel extract from aloe vera plant for controlling the Staphylococcus aureus (bacterium). African Journal of Microbiology Research 3(5), 228-232.

6. Jayakumari S, Prabhu K, Rao MRK, Bhupesh, Kumaran D, Ramesh A. 2017. The GC MS analysis of a rare medicinal plant aloe barbadensis Journal of Pharmaceutical Sciences and Research 9(7), 1035-1037.

7. Irshad S, Butt M, Younus H. 2011. In-vitro antibacterial activity of aloe barbadensis miller (aloe vera) International Research Journal of Pharmaceuticals 1(2), 59-64.

8. Thilagavathi G, Krishna Bala S, Kannaian T. 2007. Microencapsulation of herbal extracts for microbial resistance in healthcare textiles Indian Journal of Fibre \& Textile Research 32, 351-354.

9. Haufe H, Muschter K, Siegert J, Böttcher H. 2008. Bioactive textiles by sol-gel immobilized natural active agents Journal of Sol-Gel Science and Technology 45(1), 97-101.

10. Karolia A, Mendapara S. 2007. Imparting antimicrobial and fragrance finish on cotton using chitosan with silicon softener Indian Journal of Fibre \& Textile Research 32, 99-104.

11. Kamble KKM, Vishwanath B, Patil CCS. 2013. Antimicrobial activity of aloe Vera leaf extract International Journal of Applied Biology and Pharmaceutical Technology 4, 286-290.
12. Fatemeh NB. 2013. Antibacterial activities and antioxidant capacity of aloe vera. Organic and Medicinal Chemistry Letters 3, 1-8.

13. Krishnaveni V, Aparna B. 2014. Microencapsulation of copper enriched aloe gel curative garment for atopic dermatitis Indian Journal of Traditional Knowledge 13(4), 795-803.

14. Ibrahim W, Sarwar Z, Abid S, Munir U, Azeem A. 2017. Aloe vera leaf gel extract for antibacterial and softness properties of cotton Journal of Textile Science and Engineering 7(3), 1-6.

15. Ganesan P, Tamil Selvi C, Ramachandran T. 2010. Microencapsulation of copper enriched herbals for curative garments Indian Journal of Traditional Knowledge 11(3), 532-536.

16. Sathianarayanan MP, Bhat NV, Kokate SS, Walunj VE. 2010 Antibacterial finish for cotton fabric from herbal products Indian Journal of Fibre \& Textile Research 35, 50-58.

17. Narsih, Kumalaningsih S, Wignyanto, Wijana S. 2012. Identification of aloin and saponin and chemical composition of volatile constituents from aloe vera (1.) peel Journal of Agricultural Food and Technology 2(5), 79-84.

18. Ravi S, Kabilar P, Velmurugan S, Kumar RA, Gayathiri M. 2011. Spectroscopy studies on the status of aloin in aloe vera and commercial samples Journal of Experimental Sciences 2(8), 10-13.

19. Sathianarayanan MP, Bhat NV, Chaudhari BM. 2011. Development of durable antibacterial agent from ban-ajwain seed for cotton fabric Indian Journal of Fibre \& Textile Research 36, 234-241.

20. Lebre, Filipa, Bento D, Jesus S, Borges O. 2012. Chitosan-based nanoparticles as a hepatitis B antigen delivery system Methods in Enzymology 509, 127-142.

21. Hildebrand GE, Tack JW. 2000. Microencapsulation of peptides and proteins International Journal of Pharmaceutics 196(2), 173-176. 